\title{
Interlocuções formativas contidas nos Projetos Políticos Pedagógicos dos cursos de Licenciatura em Ciências Agrícolas/Agrárias no Brasil ${ }^{\mathrm{i}}$
}

\author{
(iD) Danieli Cristina de Souza ${ }^{1}$, iD Dimas de Oliveira Estevam ${ }^{2}$, ID Kelly Gianezini ${ }^{3}$ \\ 1, 2, 3 Universidade do Extremo Sul Catarinense - UNESC. Programa de Pós-Graduação em Desenvolvimento Socioeconômico \\ (PPGDS). Avenida Universitária, 1105, Universitário. Criciúma - SC. Brasil.
}

Autor para correspondência/Author for correspondence: dcs@unesc.net

RESUMO. As diretrizes da ação pedagógica voltada à educação do campo para o campo devem estar pautadas na construção socioeducativa em diálogo constante com os saberes científicos e empíricos. Nesse contexto, objetiva-se identificar interlocuções formativas à educação do campo/rural para o campo nos cursos de Licenciatura em Ciências Agrícolas/Agrárias no Brasil por meio da análise de seus Projetos Políticos Pedagógicos (PPPs). A pesquisa tem caráter qualitativo, com abordagem descritiva e exploratória, cujo referencial teórico tem como foco o projeto educacional rural e do campo, bem como documental, cujas fontes foram obtidas na Plataforma do Instituto Nacional de Estudos e Pesquisas Educacionais Anísio Teixeira, no site do Ministério da Educação e nos PPPs emitidos pelas Instituições de Ensino Superior (IES) pesquisadas. O critério ao determinar o recorte temporal do estudo foi baseado na acessibilidade das últimas informações disponibilizadas no momento da coleta, ou seja, junho de 2020. Os resultados apontam que dos doze cursos investigados, todos se referem à formação para o ensino agrícola, sendo que cinco deles apresentaram características para a formação da educação do campo, citando não somente as abordagens metodológicas para essa formação, como também o eixo das políticas públicas vinculadas ao tema. Constatou-se a dualidade desordenada de conceitos e de concepções de educação do campo/rural e de ensino agrícola, estabelecidos nos PPPs, cuja reprodução tende a estar presente nas práxis dos educadores.

Palavras-chave: educação do campo, ensino rural, licenciatura em ciências agrárias. 


\title{
Formative interlocutions in the Political-Pedagogical Projects of undergraduate courses of Agricultural/Agrarian Sciences in Brazil
}

\begin{abstract}
Pedagogical guidelines for the education in/of/to the rural areas must be based on the socio-educational development and on a constant dialogue between scientific and empirical knowledge. In this context, our objective is to identify formative interlocutions in the rural/countryside education in undergraduate courses of Agricultural Sciences in Brazil, through the analysis of their Political-Pedagogical Projects (PPP). This is a qualitative research with a descriptive and exploratory approach. It focuses on the theoretical background about rural educational project. It is also a document-based study that has as its source data from Anísio Teixeira Platform, connected to the Ministry of Education, as well as PPP emitted by the higher education institutions. The criteria chosen to establish the study's time frame was the accessibility of the most recent information that were available during the process of information gathering - June, 2020. The results show that twelve of the studied courses had as their formative reference agricultural education - in terms of hegemonic production processes such as agribusiness, adopting a technicist approach. Only five of the studied courses were characterized by a formative framework aimed at the education of the rural areas encompassing several expressions of rural life, such as family agriculture, peasantry and so forth. These courses make reference not only to these specific methodological approaches, but also to public policies related to this issue. Furthermore, we also identified in the institutions' PPP a chaotic duality of concepts of education in/of the rural areas, on the one hand, and agricultural education on the other; such chaotic mixture of concepts is prone to be reproduced in the praxis of the teachers.
\end{abstract}

Keywords: countryside education, rural education, licenciate degree in agricultural sciences. 


\section{Interlocuciones formativas comprendidas en los Proyectos Político Pedagógicos de los Cursos de Grado en Ciencias Agrícolas/Agrarias en Brasil}

RESUMEN. Las pautas de acción pedagógica dirigidas a la educación rural deben basarse en la construcción socioeducativa en constante diálogo entre el conocimiento científico y el empírico. En este contexto, se pretende identificar las interlocuciones formativas respecto a la educación rural en los cursos de graduación en Ciencias Agrarias en Brasil a través del análisis de los Proyectos Político Pedagógicos (PPP). La investigación es cualitativa, descriptiva y de enfoque exploratorio, sobre el marco teórico del proyecto educativo rural y campesino. Y documental, tomando como fuente los datos de la Plataforma Anísio Teixeira, del Ministerio de Educación, y los PPP emitidos por las instituciones de educación superior. El criterio para determinar el rango de tiempo del estudio se basó en la accesibilidad de la última información disponible en el momento de la recogida, junio de 2020. Los resultados indican que, de los doce cursos investigados, todos se refieren a la formación en educación agrícola, y cinco de ellos presentaron características para la formación de la educación campesina, citando no sólo los enfoques metodológicos para esta formación, sino también el eje de las políticas públicas vinculadas al tema. Asimismo, se observa la dualidad desordenada de conceptos, de concepciones sobre la enseñanza en contexto rural y la educación agrícola establecidas en los PPP y que tienden a reproducirse en la praxis de los educadores.

Palabras clave: educación en el campo, enseñanza rural, grado en ciencias agrarias. 


\section{Introdução}

O constante movimento de luta pelo direito formativo de sujeitos do meio rural, tendo o processo educacional dialógico princípios sociais, políticos e econômicos da comunidade em que se encontra a escola, assim como o acesso a uma educação emancipadora, distanciada da reprodução difusa e dual criada historicamente entre rural e urbano, que vise potencializar as identidades do espaço ante as diferentes ruralidades, é um dos desafios na elaboração e práxis das concepções formativas e metodológicas em diferentes níveis de ensino.

Os preceitos pedagógicos, técnicos e sociopolíticos presentes nas propostas e práticas inseridas na educação formal e informal endossam um constante processo formativo de seus egressos, os quais estarão atuantes nas construções e (re)significações conjuntas com outros sujeitos, comunidades e instituições de modo a mobilizar, reproduzir e/ou equivocadamente tentar transpor ao campo paradigmas desconexos com a realidade local.

Nesse contexto, quiçá que os currículos de cursos como o de Licenciatura em Ciências Agrícolas/Agrárias ou de Licenciatura em Educação do Campo, os quais visam à formação de professores para atuarem em disciplinas do setor primário (agricultura, pecuária, zootecnia, por exemplo) e da educação básica, apresentem-se, por vezes, contraditórios aos anseios dos movimentos sociais do campo, limitantes em relação à diversidade das ruralidades existentes e um reflexo para as demandas no avanço de políticas públicas básicas e educacionais pensadas para o campo.

A respeito dos cursos supracitados, cabe salientar que a determinação para a formação docente em disciplinas do eixo técnico ou da educação básica está publicada no Censo Superior da Educação, emitido pelo Instituto Nacional de Estudos e Pesquisas Educacionais Anísio Teixeira (INEP) e pelo Ministério da Educação (MEC), a qual, a partir da base de Classificação Internacional Normalizada da Educação (ISCED - International Standard Classification of Education), em cooperação com a Organização das Nações Unidas para a Educação, a Ciência e a Cultura (UNESCO) e a Organização para a Cooperação e Desenvolvimento Econômico (OCDE), estabeleceu, desde o ano 2000, uma classificação nacional dos cursos superiores no Brasil.

Entre os cursos classificados para a formação de professor de disciplinas profissionais estão as Licenciaturas em Ciências Agrícolas/Agrárias, que, 
sumariamente, enquadram-se na área geral da educação; na área específica de formação de professores e na de ciências da educação; e na subárea detalhada de formação de professor de disciplinas do setor primário (Brasil, 2019; 2020). Por conseguinte, os profissionais egressos desses cursos possuem frentes multidisciplinares de possibilidades de atuação. Para as inserções em instituições de ensino, pesquisa e extensão nos três níveis educacionais, cabe um dinamismo que fomente e valorize um campo que compõe complexidades históricas, culturais, sociais, econômicas e políticas.

Perante as conjunturas que diferem e ao mesmo tempo complementam as primícias centrais sobre os contextos rurais brasileiros, de forma responsiva, exige-se do trabalho pedagógico - o qual está amparado em seus limites e possibilidades da legislação, das condições institucionais e em seu capital social de técnicos e de docentes - o estabelecimento de um percurso formativo que abarque tão quanto possível a harmoniosidade de estratégias de ensino-aprendizagem, que contemple as singularidades e ao mesmo tempo as heterogeneidades presentes nas relações e estruturas que formam o espaço agrário.

Para tal, acresce-se a necessidade de construção de uma estrutura formalizada que venha orientar e instigar ações, as quais, entre tantos outros aspectos, tratem com transparência das concepções, das conjunturas e dos pensamentos técnicos, políticos e formativos, preconizados no conjunto de perspectivas que compõem, como exemplo, o âmbito dos Projetos Políticos Pedagógicos. Em vista disso, o objetivo do artigo é identificar interlocuções formativas à educação do campo/rural para o campo nos cursos de Licenciatura em

Ciências Agrícolas/Agrárias no Brasil por meio da análise dos Projetos Políticos Pedagógicos (PPPs) das IES pesquisadas.

Ao abordar sobre as Licenciaturas em Ciências Agrícolas/Agrárias, justificase, ao observar a criação dos referidos cursos, a finalidade de atender ao art. 59 da Lei de Diretrizes e Bases da Educação Nacional (LDB), Lei $\mathrm{n}^{\circ}$ 4.024, de 20 de dezembro de 1961 (Brasil, 1961), a qual menciona a necessidade de formar professores para atuarem em escolas agrícolas e contribuírem para o processo técnico-pedagógico no ensino do campo.

Assim, compreende-se a necessidade de profissionais com formação técnicocientífica para atender ao avanço da agricultura no País e às necessidades do mercado de trabalho - Lei de Diretrizes e Bases da Educação Nacional, nº 9.394, de 20 de dezembro de 1996 (Brasil, 1996). Contudo, as mudanças sociais e 
econômicas refletidas em certo modo pelas complementaridades legais das políticas educacionais buscaram, em parte, a (re)significação do ensino agrícola e do ensino rural para a educação do campo, alinhada não apenas pela ótica crítica e emergencial para o cumprimento do direito unificado de acesso à educação, mas também, em especial, pelas propostas ligadas à expansão econômica e política do agronegócio (Brasil, 2007; 2009).

O debate polêmico e por vezes contrastante sobre termos como Educação Rural, Ensino Agrícola e Educação do Campo vigora perante os marcos teóricos, legislativos e práticos dessas propostas pedagógicas. Atualmente, em todo o território brasileiro, existem 79 cursos voltados à formação docente para a educação básica e 21 para professores de disciplinas do setor primário. São cursos de graduação classificados como licenciatura, destinados à educação do campo, seja para disciplinas básicas ou específicas na área agrária (Brasil, 2019; 2020). Cabe salientar que entre a diversidade de cursos que visam a essa formação há alguns intitulados "Educação do Campo", "Pedagogia do Campo", "Interdisciplinaridade e Educação do Campo", "Licenciaturas em Ciências Agrícolas/Agrárias e do Meio Ambiente”. No que se refere à inserção binômia de cursos na área da educação, tem-se a subárea de formação de professores para as disciplinas voltadas ao segmento agropecuário ou, utilizando-se o termo do INEP/MEC, ao setor primário, como é o caso da Licenciatura em Ciências Agrícolas/Agrárias.

A centralidade deste estudo compreende, então, a preocupação quanto à obviedade do ensino dos conteúdos programáticos das subáreas das ciências agrárias, embora essa ação educativa não se limite à racionalidade técnica, visto que é realçada a importância do processo formativo pelas interlocuções formativas. Significa reconhecer as inter-relações das concepções das políticas educacionais que denotam as diretrizes legislativas, os aspectos conceituais e práticos das concepções educativas, tendo como exemplo a educação do campo, a educação rural e o ensino agrícola, as quais são/foram estabelecidas institucionalmente.

Nesse sentido, torna-se relevante refletir sobre as interlocuções formativas presentes no contexto das concepções manifestadas nos objetivos dos referidos cursos, que implicam as abordagens técnicas e científicas das relações pedagógicas de ensino e aprendizagem ante as conjunturas e os contextos rurais.

Como procedimentos metodológicos, a pesquisa se enquadra na abordagem 
qualitativa. Quanto ao objetivo, caracteriza-se como exploratória e descritiva (Gil, 2010). Os dados nela utilizados são predominantes de fontes documentais, tendo como critério de amostragem a acessibilidade das informações no momento da coleta. Assim, as bases pesquisadas foram a Plataforma do Instituto Nacional de Estudos e Pesquisas Educacionais Anísio Teixeira (INEP), mais precisamente a Sinopse Estatística da Educação Superior de 2018 (Brasil, 2019) e os relatórios completos do Ministério da Educação (MEC), especialmente no $e-M E C$ (Brasil, 2020).

Em relação à triagem dos cursos, ao consultar a Plataforma do INEP e os relatórios do MEC, optou-se por desconsiderar três cursos em processo de extinção. Além deles, foi necessário descartar outros seis, em virtude de o PPP ainda não ter sido publicado no momento da consulta aos sites das instituições proponentes em junho de 2020. Desses cursos, sete eram presenciais e os outros dois a distância, incluindo o intitulado Licenciatura em Ciências Agrárias e Meio Ambiente.

Portanto, foram avaliados doze cursos na modalidade presencial, distribuídos da seguinte forma: nas regiões Sul e Sudeste, cada uma com três cursos; na região Norte, um curso; e cinco na região Nordeste. Os doze cursos possuíam a nomenclatura "Licenciatura em Ciências Agrícolas" ou "Ciências Agrárias".

A metodologia utilizada para a coleta dos dados se baseou na análise de conteúdo (Bardin, 2002), tendo como produto a construção do esquema analítico, que contou primeiramente com a leitura atenta do arcabouço teórico e legislativo. Por meio da escolha amostral e dos documentos analisados, da revisão das concepções educacionais para a educação rural e do projeto educativo do campo, bem como das citações expressas nos PPPs, estabeleceram-se articulações e conexões entre tópicos e temáticas, escolhidos pela sua relevância, homogeneidade e representação no contexto investigado, de modo a compor, como tratado por Bardin (2002), a expressão das relações e a análise categorial.

Para tanto, estabeleceram-se as categorias de análise mais coerentes e integrativas com os pressupostos da pesquisa, contidas nos PPPs das Licenciaturas em Ciências Agrícolas/Agrárias das IES pesquisadas. Destaca-se que neste estudo as categorias definidas surgiram no decorrer da análise ou, como apontado por Moraes e Galiazzi (2005), são “emergentes dos dados”. A fim de identificar as interlocuções formativas 
que pretendem atender à formação do egresso, quanto aos objetivos dos cursos e às dimensões técnicas pedagógicas apresentadas nos PPPs, o conjunto de categorias que emergem significados dos dados como campo de análise dos objetivos são: Educação do Campo; Ensino Agrícola/Agrário; Docência; Pesquisa e Extensão. Como dimensões técnicas pedagógicas aparecem: Técnicas Agropecuárias; Contexto Sociocultural e Político; Desenvolvimento Rural; Agroecologia e Meio Ambiente.

Visando atingir a intenção do estudo, o texto está organizado em cinco seções, incluindo esta introdutória, a qual aborda sobre o tema, os objetivos e os procedimentos metodológicos da pesquisa. Na segunda seção, então, discorre-se sobre as concepções das políticas educacionais e dos aspectos teóricos sobre educação rural e educação do campo nos eixos técnicos e socioculturais para o projeto educativo de ensino para o povo do campo. Na seção seguinte, descrevem-se e analisam-se os cursos de Licenciatura em Ciências Agrícolas/Agrárias no contexto descrito em seus PPPs, vinculados às respectivas instituições de ensino superior, e a abordagem conceitual sobre agrícola e agrário. Na sequência, a outra seção evidencia as interlocuções formativas sobre os objetivos e as dimensões técnicas pedagógicas mencionadas nos referidos cursos. Na última seção, são apresentadas as considerações finais do trabalho, com a síntese de resultados, limitações e questões ainda a serem consideradas em pesquisas futuras sobre a temática.

\section{Interlocuções nas concepções legislativas e educativas à educação rural e do campo}

A compreensão do projeto educativo do campo se configura de forma a contrapor a proposta de educação rural e ensino agrícola, estabelecida nas diretrizes legislativas e em alguns currículos e práticas de cursos vinculados à formação de professores e ou à formação técnica na área das agrárias. Importante esclarecer que não se trata de uma disputa de concepção alternativa entre uma e outra proposta de educação, mas sim de projetos distintos ante suas finalidades.

A questão posta nas interfaces dessas concepções está entre os objetivos e as lutas dos movimentos sociais em relação à vinculação desses princípios como eixos principais e não complementares durante a formação básica e superior, seja no estabelecimento das teorias e ou das práticas presentes no processo formativo, as quais, consequentemente, são reproduzidas nas práxis dos seus profissionais. 
A concepção de educação rural tende a sobressair-se ainda nos currículos, visto sua construção possivelmente pela reprodução pedagógica em perspectivas análogas às vivências no/do campo, predominando uma visão tecnicista de ensino alinhado aos arranjos produtivos do agronegócio, a qual limita a dimensão dos saberes culturais da realidade dessa população (Alencar, 2010; Arroyo, 2012) e distancia-se de uma proposta pedagógica social de projeto educativo do campo.

Já a educação do campo deve ser pensada e executada sob uma perspectiva de lutas e ações de seu povo ao longo da história. Caldart (2009; 2012), ao discorrer sobre o tema, evidencia que a terminologia e a atuação da educação do campo devem ser reconhecidas por um desenvolvimento de projeto educativo, reflexivo e atuante no espaço social e produtivo para aqueles que ali se reconhecem como parte. Ressalta, também, a necessidade de essa educação visar à construção de escolas e de políticas públicas sólidas para a formação humanística, com reflexão crítica e emancipatória.

Os movimentos sociais lutam para que os sistemas de ensino básico e superior discutam e vigorem um currículo para a área rural que não seja mera adaptação do currículo pensado para área urbana, e que a formação de professores não se paute na fragmentação do conhecimento teórico, fundamentada em uma tendência tradicional de educação ou nas particularidades das disciplinas em detrimento da negação da realidade sóciohistórica e política do povo que vive nesse espaço. Esses novos currículos devem formar profissionais capazes de instigar e influenciar novas políticas educacionais, ou seja, reafirmar o elo sociopolítico desses sujeitos (Alencar, 2010; Arroyo, 2012).

Assim, o processo formativo reproduzido nas práxis superará uma visão inferiorizada do ensino nesses espaços. Consequentemente, configurou-se em uma formação integral, capaz de promover a articulação entre escola e comunidade, educação como prática social de interrelação dos conhecimentos populares com os técnicos científicos na construção de possibilidades de permanência, de sobrevivência produtiva e social nos territórios rurais (Molina, 2008; Pistrak, 2000).

Ao contrário disso, a vivência escolar infere criando barreiras que dificultam os processos educacionais para uma classe trabalhadora, em especial os povos das águas, do campo e das florestas, por exemplo, na possibilidade dicotômica de objetivos e proposições inscritos nos PPPs dos cursos de formação de professores - 
Educação das Agrárias -, com os valores de projetos societários presentes no público-alvo desse ensino.

O contexto da educação rural historicamente estabelecida, assim como o da educação profissional dos trabalhadores do campo, tem o desafio de romper a posição hierarquizada dos valores e da produção de vida na cidade sob as conjunturas (éticas, políticas, culturais, econômicas) do campo (Caldart, 2009) a partir do desenvolvimento de currículos e de práticas que possam mediar as necessidades dessa população em relação às políticas governamentais hegemônicas, em vez de predominar uma educação rural que vislumbre a formação de profissionais em função do capital.

Perante essa situação, torna-se emergente compreender o trabalho como princípio formador e educativo por uma matriz pedagógica com metodologias de ensino que considerem a terra como espaço de vida, conciliando a vivência de opressão aos movimentos sociais e aos vínculos estruturais de trabalho agrário. $\quad \mathrm{Na}$ formação emancipatória em prol de um processo construtivo de educação omnilateral, tem-se o sujeito autônomo, integral em vista das destrezas produtivas e socioculturais (Santos, 2012), que é desafiado pelo presente sistema agrário hegemônico, mas também instigado pela ação dos movimentos sociais, impulsionando novas abordagens teóricas e práticas pedagógicas.

As políticas educacionais para o meio rural tiveram a sua construção histórica, política e social articulada a currículos com intenções educativas pautadas no vínculo indissociável de manutenção do povo do campo instalados no campo. Até a década de 1990, o poder condicionado nos atos legislativos quanto à negação de projeto educativo para o sujeito do meio rural predominou. Contudo, nas décadas seguintes, houve a amenização desse caráter pelas lutas dos movimentos sociais e um projeto de representação sociopolítica além das dimensões da produção agrícola (Matos \& Rocha, 2020).

É evidente a disputa travada entre a educação do campo em prol dos interesses da classe trabalhadora, dos movimentos sociais e do resgate do campesinato em relação à estrutura das políticas públicas fortalecidas pelos interesses das cadeias produtivas agroindustriais e do agronegócio. A discussão sobre isso gera dilemas estabelecidos entre e pelas frentes das forças em defesa da educação pública, as quais recusam as concepções da educação rural em prol de não se perderem as particularidades do campo pelos elementos produtivistas estabelecidos no projeto educativo. 
Nessa perspectiva, autores como Duarte (2008) e Kerstenetzky (2005) apontam que a intervenção estatal deve conceder uma proposta de políticas públicas específicas, especialmente a grupos historicamente não atendidos em direitos universais. A exemplo do caso brasileiro, a garantia na constituinte ao acesso à educação encontra dificuldades históricas nas conjunturas e estruturas para garantir o direito à educação em parâmetros mínimos e na prática tem limites para atender às particularidades da população do campo.

Autores como Calazans (1993), Gritti (2003), Petty, Tomnim e Vera (1981) revelam o conceito de educação rural, que transcende a disponibilidade de acesso à educação aos sujeitos do meio rural, pautado nas diretrizes de ensino básico, alinhando-se ao manejo e às técnicas agrícolas. A educação rural deve ser pensada, discutida e implementada entre as diferentes esferas (municipais, estaduais e federais) e, sobretudo, pelos seus diferentes agentes (povo do campo, das águas e das florestas, gestão pública, educadores e movimentos sociais).

Tal ação se consolidou para estabelecer o diálogo entre saberes científicos e vivências produtivas, socioculturais e históricas das famílias e comunidades. Por isso trazem como problemática a capacitação docente para que atuem nesse meio e a reprodução do Estado no modelo hierarquizado de concepções externas à realidade regional/local.

Nesse sentido, é evidente a motivação dos movimentos sociais pela inserção de uma educação do campo diferente da educação rural constituída pelas políticas públicas e ofertada por (re)significações. Isto posto, desde que seja a partir das concepções pedagógicas e formativas nas práxis dos seus educadores nas quais a dicotomia entre a luta dos movimentos sociais e a tentativa do Estado de oferecer uma educação mínima ao meio rural perpassam múltiplas direções e sentidos, pois, ao mesmo tempo que se considera um elemento de direito, ao exercê-lo, está se descaracterizando a identidade do sujeito que pertence a esse meio, tendo em vista um sistema de escolarização condicionado a elementos urbanocêntricos, os quais, quando inseridos no currículo para o sentido da atividade agrícola, direcionam a técnica, sem considerarem as experiências e os saberes dos educandos.

A "tríade estruturante: campo políticas públicas - educação" debatida por Molina (2012) nos permite analisar os avanços e retrocessos dessa disputa entre dispositivos legais, com destaque para as 
legislações, como a Lei de Diretrizes e Bases da Educação Nacional (LDB), $\mathrm{n}^{0}$ 9.394, de 20 de dezembro de 1996; o Parecer $\mathrm{n}^{\circ}$ 36, de 04 de dezembro de 2001, que contém as Diretrizes Operacionais para a Educação Básica nas Escolas do Campo - a Educação do Campo; e o Decreto n ${ }^{\circ}$ 7.352, de 04 de novembro de 2010, os quais asseguram o projeto de educação do campo, reconhecem as especificidades sociais e culturais e os modos de produção desse espaço, assim como a intencionalidade e a ação estatal para minimizar as consequências das desigualdades históricas perante as particularidades dos povos do campo ante a luta dos movimentos sociais em prol da identidade no espaço socioeducativo.

Entretanto, os desafios ultrapassam as formas, sendo inseridos especialmente nos currículos, no processo formativo dos sujeitos que participam desse ensino. E, nesse contexto, além da legislação, é preciso superar a reprodução de metodologias e de conteúdos tecnicistas distantes da realidade (Souza, 2019).

Nessa perspectiva, a inserção dos processos educativos aos trabalhadores do campo envolve técnicas com experiências e saberes culturais, políticos e produtivos inerentes à comunidade, de modo que venham romper com o modelo abstrato de conteúdos e métodos, aproximando as abordagens científicas e as vivências intrínsecas inseridas no processo de aprendizagem, sem restringirem-se a uma educação técnica e tecnológica meramente produtivista, sendo construídas para o campo, seus sujeitos e suas múltiplas relações.

Para tanto, faz-se indispensável o planejamento, a execução e a reflexão de um currículo que inclua elementos sociais, culturais e econômicos do contexto discorrido. O projeto de educação do campo/rural deve perpetuar na formação dos futuros docentes que estarão direta ou indiretamente atuando no segmento agrário para que transcendam em sua trajetória formativa a hegemonia do modelo produtivista agrícola enraizado ao ensino profissionalizante, possibilitando a visibilidade de uma educação conectada à realidade e de demandas da população no/do campo.

Entre esses e outros fatores, é constante e candente a organização da classe trabalhadora para uma educação que reformule e possibilite alternativas às pedagogias e às práticas tradicionais e liberais, que estão a serviço da manutenção das estruturas de poder político, de exploração do trabalho e de domínio cultural (Paludo, 2001).

Para Frigotto (1999), a educação como prática social é uma atividade 
passível de integração da instituição educativa com a comunidade, cuja junção de diversos fatores que articulam saberes científicos e populares cria a possibilidade de mudar o contexto no qual estão inseridos. $\mathrm{Na}$ construção de relações que visem a esse desenvolvimento de trabalho, educação e políticas, de maneira multidisciplinar, consequentemente, provocam quase que unicamente ao docente e ao discente a insurgência de compreensão das diversidades culturais, sociais e ambientais existentes, tendo em vista a dicotomia criada para a compreensão das teorias atreladas aos cursos, sejam eles para a formação de professores do ensino básico ou de disciplinas do setor primário, na tendência da reprodução de metodologias técnicas e pedagógicas às ruralidades brasileiras.

Ao analisar aspectos relativos à educação do campo/rural, evidenciou-se a necessidade de uma educação integrada aos territórios, aos valores étnicos, às condições produtivas, sociais e da vida no campo. A educação do campo tem sido desenvolvida a partir de uma ótica urbana, portanto, desconhecendo suas especificidades e direcionando suas ações pedagógicas no viés do ensino rural e agrícola. Esse tem sido o teor das agendas de ensino em muitos países, em particular no Brasil. Esses aspectos podem ser percebidos quando analisados os conteúdos curriculares do Ensino Fundamental e Médio, que valorizaram aspectos e saberes urbanos em detrimento daqueles do campo (Estevam, 2012).

Em outro nível e outra concepção educacional, também se evidencia que, tradicionalmente, as escolas rurais e as agrotécnicas não têm sido capazes de preparar os jovens para permanecerem no campo. É comum os conteúdos nessas escolas serem inadequados à realidade da agricultura familiar e dos povos tradicionais. Eles afastam os jovens de suas realidades, posto que a aplicabilidade dos conhecimentos produzidos nessas instituições dificilmente são adaptáveis à pequena produção rural. Ademais, provocam conflitos entre saberes dos pais e os conhecimentos aprendidos pelos filhos, levando o jovem, na maioria das vezes, a abandonar o campo (Estevam, 2012).

As evidências relatadas para o ensino básico nem sempre no campo, mas refletidas nos cotidianos do campo, estão sob a desarticulação entre propostas pedagógicas, conteúdos técnicos e a realidade vivida dos estudantes e insurgem sobre dois pilares sincrônicos. Um sob a ótica do modelo econômico da produção agropecuária e o outro quanto à prática docente, a qual remete a experiências de 
formação docente que passaram na trajetória formativa.

Nesse aspecto, tem-se um limitador educativo, visto que ao não serem consideradas as interações socioculturais e políticas que envolvem a sobrevivência e a manutenção das famílias no campo, a tendência é para uma formação de preceitos meramente técnicos, voltados à produção na agricultura, em um contexto meramente produtivista e técnico (Braga \& Souza, 2017). E nesses limites formativos percorrem um caminho emergente de transformação, como mencionado por Wanderley (2009), o qual perpassa essencialmente a valorização daqueles que vivem do campo. Para tanto, é preciso a abordagem de contextos e de práticas que “... trata-se da construção de novas facetas de uma identidade social que pretende representar uma posição crítica em relação ao modelo dominante de agricultura moderna" (Wanderley, 2009, p. 194), (re)significando as singularidades sociais, políticas, de território (agrário) e econômicas (agrícolas) articuladas a um projeto socioeducativo no campo.

Em relação ao segundo aspecto, Hernández aponta a primordialidade em "... considerar que os docentes não partem do zero, pois possuem sua formação e uma experiência durante a qual adquiriram crenças, teorias pedagógicas e esquemas de trabalho" (Wanderley, 2009, p. 4). Essas e outras questões devem ser observadas no processo de formação de docentes do campo para não se perpetuaram práticas profissionais desconexas com a realidade.

Diante do exposto, articular tais necessidades à formação de professores que atuam diretamente na educação do campo, ou de sujeitos que estabelecem relações de dimensão técnica e/ou pela vivência rural, perpassa, entre outros aspectos, os desafios das abordagens supracitadas. Nesse cenário, cabe, neste estudo, refletir sobre as concepções de cursos como o de Licenciatura em Ciências Agrícolas/Agrárias, direcionadas à formação de profissionais em disciplinas técnicas e que estão diretamente formando sujeitos atuantes em diversas frentes que tangenciam o fomento do desenvolvimento rural no Brasil.

Perante as especificidades que as diferenciam, assim como as demandas das distintas ruralidades existentes, a ação educativa do campo tem suas intencionalidades. A questão central está em identificar como estão pautados os objetivos e as dimensões técnicas e pedagógicas contidos nos PPPs dos referidos cursos.

A observação das interlocuções entre as diferentes concepções teóricas e as 
possibilidades metodológicas será conduzida pela análise dos PPPs, que apontam os procedimentos normativos de embasamento legal e as deliberações conceituais, procedimentais e atitudinais que orientaram as ações de todos os envolvidos. A análise dos PPPs deve atingir os objetivos conceituais perante os princípios epistemológicos da concepção de educação, do processo de ensinoaprendizagem, do planejamento da ação pedagógica, das diretrizes sobre os conteúdos importantes para a formação esperada do indivíduo inserido, das propostas de como as instituições objetivam e possibilitam esses conjuntos de relações documentais, estruturais e interpessoais que ocorrem e desenvolvemse pelas interlocuções formativas do egresso.

\section{Caracterização do conceito agrícola e agrário e a distribuição territorial das licenciaturas analisadas}

Como cursos de "Formação de professor e ciências da educação, para disciplinas profissionais", o MEC (Brasil, 2020) classifica vinte e um cursos, dentre os quais, perante a distribuição regional, o Nordeste predomina (com oito cursos), seguido pelo Norte (seis cursos), pelo Sul e Sudeste (três cada região) e pelo CentroOeste (um curso).
Referidos cursos se apresentam com diferentes nomenclaturas, sendo quatorze intitulados "Licenciatura em Ciências Agrárias"; seis são reconhecidos como "Licenciatura em Ciências Agrícolas" e um como "Licenciatura em Ciências Agrárias e do Meio Ambiente". Em relação à modalidade, dezenove deles são ofertados de forma presencial e apenas dois a distância. Importante destacar que do total dos cursos cadastrados, três estão em processo de extinção.

No cenário brasileiro, a difusão da nomenclatura dos cursos nos faz perceber as possibilidades de os cursos mais antigos estarem intitulados como "agrícolas" em decorrência do alinhamento ao processo de desenvolvimento econômico e social da cadeia produtiva agropecuária do País entre a década de 1960 e 1970, tendo em vista a constatação entre a terminologia agrícola e agrária não apenas no que tange ao significado real da palavra, mas às narrativas e aos debates sobre o meio rural agrícola e agrário brasileiro.

Nesta averiguação, importante destacar que, no Brasil, das Licenciaturas em Ciências Agrícolas/Agrárias, os cursos mais antigos estão intitulados "Licenciatura em Ciências Agrícolas". O primeiro deles teve origem na região Sudeste, em 1963, na Universidade Federal Rural do Rio de Janeiro (UFRRJ), seguido 
pela região Nordeste, em 1970, na Universidade Federal Rural de Pernambuco (UFPE).

Posteriormente, por meio da Lei $\mathrm{n}^{0}$ 11.892, de 29 de dezembro de 2008, que institui a Rede Federal de Educação Profissional, Científica e Tecnológica, criando os Institutos Federais de Educação, Ciência e Tecnologia, a partir dos anos de 2010, foram abertas turmas para a formação de Licenciados/as em Ciências Agrícolas nas regiões Sul e Sudeste e, em 2011, na região Centro-Oeste. Com relação ao vínculo institucional, constatouse que dos 21 cursos cadastrados, todos estão em instituições de ensino públicas, sendo que nove são ofertados por universidades federais, oito por institutos federais e quatro por universidades estaduais.

Observa-se, ainda, que alguns dos cursos investigados, inicialmente, foram intitulados "Ciências Agrícolas", mas que depois solicitaram ao Ministério da Educação (Brasil, 2020) a alteração para "Ciências Agrárias". Foram identificados três pedidos entre os seis cursos assim intitulados. Já no quesito abordagem dos PPPs, predomina o uso agrário nas expressões utilizadas e nas ações propostas.

Acresce-se que as transformações físicas, produtivas, socioeconômicas do meio agrícola/rural influenciaram as preocupações quanto ao uso de terminologias em estudos teóricos e empíricos sobre o que está intrínseco nos contextos e nas subjetividades rurais. O termo agrícola se refere à agricultura, já o agrário, por sua vez, está em relação com o campo, com o território rural, envolvendo não apenas suas atividades agrícolas, mas suas relações territoriais, sociais, ambientais, culturais e políticas (Ferreira \& Ferreira, 2009).

A partir do significado dos termos agrícola e agrário, é possível perceber que o segundo termo se apresenta de modo mais genérico e abrangente, possibilitando uma abordagem além dos processos produtivos da agricultura, inserindo a potencialização das ruralidades existentes em diferentes espaços.

É preciso entender a "ruralidade" como um processo dinâmico em constante reestruturação dos elementos da cultura local, com incorporação de novos valores, hábitos e técnicas (Carneiro, 2008), diferentemente da dualidade fundadora da sociologia rural expressa nas diferenças entre o rural e o urbano, que, por sua vez, sustentam-se em um conjunto de oposições. Com efeito, como apontado por Martins (1981), expor a crítica à sociologia rural, instituída historicamente pela lógica dos opostos sociais, econômicos e 
culturais, oportuniza novas visibilidades e a superação do que é considerado dual ou dicotômico.

Portanto, é necessário um sentido mais dinâmico do termo agrário, alinhando-se ao perfil profissional voltado às dimensões técnicas pedagógicas, visando valorizar a diversidade cultural, bem como garantir condições sociais dentro do contexto histórico, político e econômico. Ou seja, desempenhar ações de caráter multidisciplinar na perspectiva de questões sociopolíticas presentes no campo brasileiro.

Desse modo, quando se faz a associação entre rural e agrícola como sendo sinônimos, está se reduzindo o rural às atividades agrícolas. Ou seja, está se definindo o rural pela ótica da escassez, da falta e do atraso (Carneiro, 2008). Da mesma forma, na substituição do termo agrícola por agrária, no quesito de termologia, o agrário estaria mais próximo do rural, e o agrícola se trata de uma formação reduzida aos aspectos da produção.

Para o processo formativo de profissionais que atuarão na docência, pesquisa e extensão, intensifica-se o olhar de integralidade para além dos aspectos produtivos, voltados ao/à fomento/intervenção e à participação do desenvolvimento rural sem distinção, sobretudo, da integração social e de espacialidades. Tal contexto é significativo ao serem analisadas as informações contidas nas interlocuções tratadas no decorrer deste estudo.

Interlocuções formativas quanto aos objetivos e às dimensões técnicas pedagógicas nas Licenciaturas em Ciências Agrícolas/Agrárias

Com base nas informações contidas nos PPPs dos doze cursos presenciais intitulados Licenciatura em Ciências Agrícolas e/ou Ciências Agrárias, cinco deles estão localizados na região Nordeste, três na região Sul, três na região Sudeste e um na região Norte. Conforme informações sintetizadas no esquema analítico abaixo, evidencia-se em todos os cursos a menção à formação para o ensino agrícola.

Alguns cursos apresentaram características para a formação da educação do campo, citando não somente as abordagens metodológicas para essa formação, como também especificando através de exemplos políticas públicas vinculadas a essa concepção educativa. Dois deles estavam situados na região Sul, enquanto as regiões Sudeste, Norte e Nordeste possuíam um curso cada.

Os estudos realizados por Caldart (2009; 2012) apontam para o surgimento da expressão educação do campo como 
não sendo uma categoria teórica, mas sim prática. A expressão é datada da década de 1990, considerada recente nas discussões formais e nas inserções curriculares, assim como no início dos anos 2000, quando houve a mudança de Educação Básica do Campo para Educação do Campo.

Os fundamentos que sustentam o projeto educativo do campo estão presentes mais ativamente em debates que apontam as contradições no processo de formação dos povos do campo. Em outros termos, trata-se de uma educação formadora construída coletivamente em contraponto a um modelo tecnicista e produtivista. Portanto, é uma concepção de formação que emerge da lógica das agriculturas familiares camponesa, quilombola, indígena, do povo das matas e das águas e dos povos tradicionais.

O propósito apresentado visa contrapor-se ao modelo da educação rural do ensino agrícola, em um movimento para romper com os pressupostos deslocados inseridos em propostas curriculares e pedagógicas. Isso não remete necessariamente à compreensão de uma transição de concepções educativas ou, simplesmente, de inclusão de contextos e subjetividades de todo o tipo de população rural. O que está posto exige uma complexa interação entre variáveis que percorrem os saberes e as experiências vivenciadas (tanto pelos docentes como pelos educandos) em combinações simbólicas e concretas das práticas produtivas e da solidariedade comunitária.

Nesse sentido, a centralidade dos PPPs do ensino agrícola revela a consolidação da lógica dominante da hegemonia agrícola, que dificulta a construção de novas referências. Consoante a essa interpretação, destaca-se a ausência nos objetivos analisados de tratativas reflexivas e concretas sobre os povos tradicionais e da agricultura familiar. Nos PPPs há menções de termos genéricos à cadeia produtiva e às questões agrárias, e sobre estas é necessário considerar toda a abrangência e as perspectivas possíveis do debate sobre o território rural, nem sempre compreendido como espaço social, político e econômico.

Dos cursos de licenciatura estudados, como esperado, em virtude de sua modalidade, todos apresentam como eixo predominante a formação para professores. Oito cursos também relacionam a importância da indissociabilidade do perfil desse profissional para ações de pesquisa e extensão no campo. 
Quadro 1 - Esquema analítico das interlocuções formativas nos PPPs dos Cursos de Licenciatura em Ciências Agrícolas e Agrárias

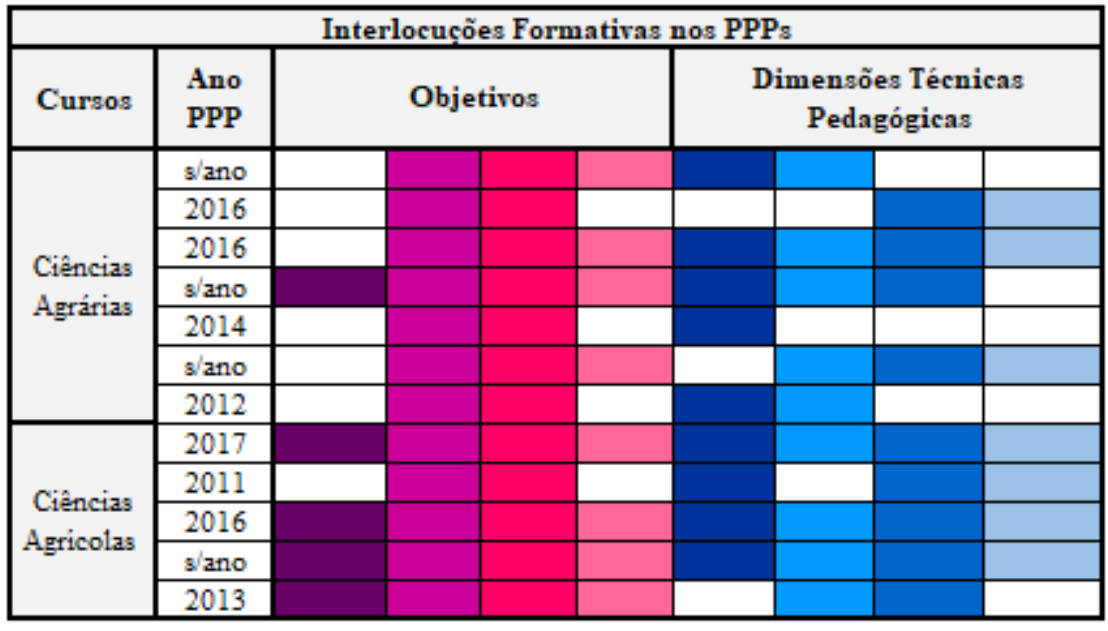

Legenda das categorias dos objetivos e dimensões técnicas pedagógicas

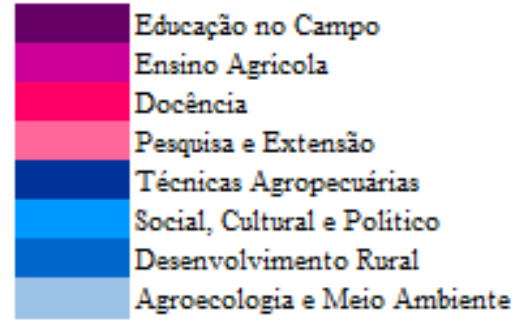

Fonte: Documentos oficiais dos cursos. Elaborado pelos autores em 2020.

Nas análises no âmbito das categorias atribuídas às dimensões técnica, sociocultural, política, desenvolvimento rural e agroecologia e meio ambiente, abordadas na fundamentação dos documentos institucionais, conforme o esquema analítico, constatou-se uma conexão relevante e singular entre todas as dimensões técnicas e pedagógicas. Contudo, essa integração está presente em apenas quatro cursos, dos quais três com abordagem diretiva à educação do campo.

Já os cursos com formação focada mais nos aspectos técnicos também apresentam justificativa construída no eixo do desenvolvimento rural. E os que estão vinculados ao desenvolvimento rural, em sua maioria, correlacionam as interlocuções dessas dimensões técnicas pedagógicas com o eixo agroecológico.

Ao abordar o tema do desenvolvimento rural, o qual é um conceito amplo e dinâmico, busca-se reverberar um conjunto de processos sociais que respeitem e articulem não apenas no aspecto produtivista, mas considerando as esferas sociopolíticas e os modos de vida do campo, com o intuito de auxiliar na compreensão quanto aos 
objetivos da formação dos licenciados em Ciências Agrícolas/Agrárias.

Ainda nessa dimensão, fica aparente a dominância e/ou integração das abordagens voltadas ao desenvolvimento rural, com foco para a agroecologia e princípios voltados à conservação e proteção do meio ambiente. No total, foram identificados sete cursos com essas características, além de dois com perfil voltado às técnicas agropecuárias. Em nenhum momento, no decorrer de seus PPPs, os cursos apresentaram uma ligação entre $\mathrm{o}$ desenvolvimento rural $\mathrm{e} a$ agroecologia.

Nas interlocuções formativas expostas quanto aos objetivos e às dimensões técnicas pedagógicas das Licenciaturas em Ciências Agrícolas e Agrárias existe, em sua totalidade, a concepção de ensino agrícola e de docência aos egressos.

$\mathrm{Na}$ identificação quanto às concepções de educação do campo, apenas cinco cursos fazem menção a essa proposta, expressando concomitantemente tratativas técnicas pedagógicas alinhadas aos eixos socioculturais e políticos e o contexto de desenvolvimento rural. Destaca-se que entre os cinco, apenas dois cursos não se referem à agroecologia e ao meio ambiente, e um não estabelece diretriz alguma entre as dimensões do segmento agropecuário com o meio ambiente e a agroecologia.

O perfil pretendido para os egressos está vinculado a princípios descritos de maneira dual e complementar em seus PPPs, com ênfase ao desenvolvimento rural com caráter predominantemente econômico e produtivista. Contudo, é passível de intervenção pela ação educativa para as dimensões sociopolíticas, visto que o processo multicultural do campo exige um dinamismo desses profissionais ao não se limitar à reprodução do modelo econômico dominante do sistema agrário.

Os cursos precisam superar a formação voltada para as abordagens técnicas e dar ênfase às questões ambientais e sociais, com a integração, quando possível, da visibilidade de diferentes concepções, haja vista o caráter de atuação dos profissionais egressos das Licenciaturas em Ciências Agrárias/Agrícolas.

Constatou-se que mesmo com o atual sistema educacional, há o desafio de propor práticas voltadas para a integralidade do ensino, da pesquisa e da extensão, e que o caráter de objetivos e finalidades dos cursos tem seu direcionamento ainda somado à modernização dos processos de produção agropecuária. Entretanto, os desafios são imensos e abrangem várias dimensões - 
política, social, econômica e pedagógica com o objetivo de superar a visão urbanocêntrica e meramente técnica sobre os antagonismos entre campo e cidade para uma proposta de ensino do campo integral e mais justa.

O perfil do profissional a ser formado acaba atrelado, em grande medida, às concepções de instituições que atuam no ensino profissional, tecnológico, cujas bases fundantes prevalecem em relação às dimensões da educação rural do ensino agrícola. É preciso avançar, inserindo-se na dinâmica das transformações dos aspectos teóricos e empíricos ao contemplar as multidimensionalidades do espaço rural. Ou, por assim dizer, como tratado pela Secretaria de Educação Profissional e Tecnológica (SETEC), em princípios que ressaltam a importância do conhecimento técnico como ferramenta para valorizar os saberes tradicionais das comunidades, sendo um profissional atuante em prol da democratização do saber (Brasil, 2009).

Nas interlocuções formativas que consubstanciam as práxis educacionais, o que se busca é uma educação interativa, construída para a prática social por meio da troca de saberes e não da apropriação do conhecimento científico como única verdade e ou, muitas vezes, apenas teorizada e não experimentada. Reitera-se que os cursos estudados têm seu enfoque enquadrado pelo MEC para a formação de docentes em disciplinas do setor primário (agricultura, pecuária, zootecnia etc.), os quais atuarão em uma gama de relações com distintos significados para seus sujeitos, visto que a realidade agrária não é homogênea.

Corroborando os estudos de Souza (2019), o qual observou que as interlocuções teóricas e os documentos institucionalizados produzidos apresentam barreiras e dualidade de conceitos e concepções de educação do campo, essa falta de consenso entre as terminologias educação rural, ensino agrícola e educação profissional para o campo gera dificuldades operacionais. Desse modo, influencia as propostas institucionais, contribuindo para a reprodução das práxis desses educadores (Souza, 2019).

Vale afirmar, distante de abarcar a totalidade da discussão, mas para trazê-la pontualmente ao debate, a necessidade de uma reflexão sobre a importância de serem estabelecidos critérios formais claros para a compreensão do significado das concepções dos processos formativos, os quais, quando não são bem definidos institucionalmente e aos sujeitos partícipes, têm as interlocuções sob a subjetividade dos PPPs, interferindo, por consequência, na construção dos currículos e das 
diretrizes metodológicas de aprendizagem estabelecidas no processo educacional e formativo.

De modo geral, a oferta gratuita de cursos de Licenciatura em Ciências Agrícolas/Agrárias pelo Estado remete à dualidade de paradigmas que não se dão de forma pacífica. São questões de conflitos sociais existentes no campo que, no que tange ao aspecto educativo, representam as condições de reconhecimento e os interesses dos processos pedagógicos em especificidades e particularidades nem sempre emancipatórias dos sujeitos.

De certo modo, a formação tecnicista, na concepção de educação profissional para o campo - termo e categoria não tratados diretamente neste estudo, porém de impacto ao debate sobressai nas reivindicações sociais como o lugar de resistência voltado à formação mais humana em consideração aos aspectos da prática social, da troca de saberes e não da apropriação do conhecimento técnico como verdade absoluta, de modo, por vezes, a desconsiderar elementos e estruturas constitutivos da realidade do campo, das ruralidades.

Assim, as interlocuções formativas têm o intuito de ampliar espaços nas instituições para que não sejam estabelecidos por critérios oficiais, mas que busquem em suas bases materiais e imateriais a construção de novas possibilidades ao instigarem a visibilidade das concepções educativas e criarem estratégias como prática vivenciada nas heterogeneidades das relações socioespaciais - como princípio formativo.

\section{Considerações finais}

Para se ter uma educação do campo para o campo, faz-se necessário trilhar um longo caminho na direção da construção de uma educação pautada na valorização das dimensões socioeducativas formais e informais (em um diálogo constante entre saberes científicos e empíricos), visando potencializar as relações socioculturais entre a teoria e a prática que contribuam para as transformações sociais, econômicas e políticas das estruturas vigentes.

A literatura estabelece a escola como espaço de reprodução social e paralelamente um lugar de trocas de saberes, de pluralidade de concepções de sociedade. O processo formativo de integração dos eixos técnicos e sociais é um elemento fundamental a ser citado nos PPPs e, por consequência, pré-requisito das práticas vivenciadas. Sobre essa narrativa não se limitam somente os cursos aqui tratados.

Em vista das interlocuções formativas contidas nos PPPs das 
Licenciaturas em Ciências Agrícolas e Agrárias, constatou-se a predominância do objetivo voltado para a visão da educação rural, no ensino técnico, pautada no segmento agrícola. Mas há de se destacar o esforço claramente estabelecido pela SETEC e por instituições de ensino superior na congruência de um caráter mais dinâmico, interdisciplinar, sobretudo aos contextos rurais, agrário, evidenciados nas dimensões técnicas pedagógicas para o desenvolvimento rural não homogêneo. De modo geral, percebe-se que categorias expressas nos objetivos estabelecidos e nas dimensões técnicas pedagógicas tendem a limitar a valorização e a integração dos saberes práticos e culturais das comunidades rurais.

Conclui-se que o desafio está na ruptura de uma lógica dominante do segmento agrícola e agrário, em prol da visibilidade das múltiplas realidades do espaço rural, na inserção de agenda e intervenção do Estado em prol da universalização do ensino básico e superior da educação do campo para o campo. Concomitantemente, ou como aqui investigado, na reconfiguração dos PPPs, dos currículos e das metodologias.

A notoriedade deste estudo está na função social e pedagógica que ele visa desvelar quanto aos cursos que envolvem a formação de docentes, extensionistas e pesquisadores em áreas e subáreas consideradas eminentemente técnicas e científicas (disciplinas do setor primário). A esse respeito não são questionadas as suas finalidades e efetividades, mas ressaltada a preocupação com as diretrizes na unilateralidade das atuações.

É preciso compreender que existem projetos formativos distintos e que a todo instante eles se constroem e reconstroem, de modo que se entrelaçam e ganham representatividade diferente em cada espaço em que atuam. Nesse sentido, o compromisso das interlocuções formativas não pode estar restrito, e de modo responsivo, apenas às instituições de ensino superior.

Cabe ao Estado o impulso de promover um delineamento legislativo em conjunto com os anseios e as transformações das distintas ruralidades para que se estabeleça um constante diálogo com a educação omnilateral, tendo o campo como espaço de vida perante a diversidade da sociedade agrária.

As limitações desta pesquisa se encontram na análise documental dos PPPs, que possibilitou fazer apontamentos sobre deliberações conceituais e procedimentais contidas nos projetos educativos dos referidos cursos. Contudo, ela não possibilitou mensurar se as diretrizes institucionalizadas pelos 
documentos estão sendo praticadas em termos pedagógicos. Sugere-se, para próximas pesquisas, analisar as disciplinas e seus conteúdos programáticos.

Aos(às) Licenciados(as) em Ciências Agrícolas e Agrárias cabe indagar sobre as interlocuções formativas inseridas em seu processo formativo ante os interesses políticos e econômicos que vigoram no contexto das políticas educacionais e nas subjetividades do meio rural.

\section{Referências}

Alencar, M. F. S. (2010). Educação do campo e a formação de professores: Construção de uma política educacional para o campo brasileiro. Ciência \& Trópico, 34(2), 207-226.

Arroyo, M. G. (2012). Formação de educadores do campo. In Caldart, R. S. (Org.). Dicionário da educação do campo (pp. 361-367). Rio de Janeiro: Escola Politécnica de Saúde Joaquim Venâncio; São Paulo: Expressão Popular.

Bardin, L. (2002). Análise de conteúdo. Trad. Luís Antero Reto e Augusto Pinheiro. Lisboa: Edições 70.

Braga, J. P., \& Souza, D. C. (2017). Contribuições da extensão rural com enfoque participativo na formação do Licenciado em Ciências Agrícolas/Agrárias. In Seminário de Educação do Campo do Instituto Federal Catarinense, 3., 2017, Abelardo Luz. Anais... Abelardo Luz, SC: IFC, p. 123127.

Brasil. Ministério da Educação. (2020). Instituições de Ensino Superior e
Cursos Cadastrados. e-Mec. Recuperado de: http://emec.mec.gov.br. Acesso em: 10 jun. 2020.

Brasil. Ministério da Educação. Instituto Nacional de Estudos e Pesquisas Educacionais Anísio Teixeira. (2019). Sinopse Estatística da Educação Superior 2018. Recuperado de: http://inep.gov.br/sinopses-estatisticas-daeducacao-superior. Acesso em: 24 maio 2020.

Brasil. Ministério da Educação. (2010). Decreto n. 7.352, de 04 de novembro de 2010. Dispõe sobre a política de educação do campo e o Programa Nacional de Educação na Reforma Agrária PRONERA. Diário Oficial da União. Brasília, DF, 05 nov. 2010. Recuperado de: https://www2.camara.leg.br/legin/fed/decre t/2010/decreto-7352-4-novembro-2010609343-norma-pe.html. Acesso em: 10 jun. 2020.

Brasil. Secretaria de Educação Profissional e Tecnológica. (2009). (Re)significação do Ensino Agrícola da Rede Federal de Educação Profissional e Tecnológica. Brasília, DF: Secretaria de Educação Profissional e Tecnológica.

Brasil. Ministério da Educação. (2008). Lei n. 11.892, de 29 de dezembro de 2008. Institui a Rede Federal de Educação Profissional, Científica e Tecnológica, cria os Institutos Federais de Educação, Ciência e Tecnologia. Diário Oficial da União. Brasília, DF, 30 dez. 2008. Recuperado de:

http://www.planalto.gov.br/ccivil_03/_Ato 2007-2010/2008/Lei/L11892.htm. Acesso em: 10 jun. 2020.

Brasil. Secretaria de Educação Continuada, Alfabetização e Diversidade. (2007). Educação do Campo: diferenças mudando paradigmas. Brasília, DF: Secretaria da Educação Continuada, Alfabetização e Diversidade. 
Brasil. Ministério da Educação. Conselho Nacional de Educação. (2001). Parecer CNE/SEB n. 36/2001, de 04 de dezembro de 2001. Diretrizes Operacionais para a Educação Básica nas Escolas do Campo, a Educação do Campo. Diário Oficial da União. Brasília, DF, 13 de março de 2002, Seção 1, p. 11.

Brasil. Ministério da Educação. (1996). Lei n. 9.394, de 20 de dezembro de 1996. Estabelece as Diretrizes e Bases da Educação Nacional. Diário Oficial da União. Brasília, DF, 21 dez. 1996. Recuperado de: http://www.planalto.gov.br/ccivil_03/leis/l 9394.htm. Acesso em: 24 maio 2020.

Brasil. Ministério da Educação (1961). Lei n. 4.024, de 20 de dezembro de 1961. Fixa as Diretrizes e Bases da Educação Nacional. Diário Oficial da União. Brasília, DF, 27 dez. 1961. Recuperado de:

http://www.planalto.gov.br/ccivil_03/LEIS L4024.htm. Acesso em: 10 jun. 2020.

Calazans, M. J. (1993). Para compreender a educação do Estado no meio rural: Traços de uma trajetória. In Therrien, J. (Org.). Educação e escola no campo (pp. 15-42). Campinas, SP: Papirus.

Caldart, R. S. (2012). Educação do Campo. In Caldart, R. S. (Org.). Dicionário da educação do campo (pp. 15-42). Rio de Janeiro: Escola Politécnica de Saúde Joaquim Venâncio; São Paulo: Expressão Popular.

Caldart, R. S. (2009). Educação do Campo: Notas para uma Análise de Percurso. Trabalho, Educação e Saúde, 7(1), 35-64. http://dx.doi.org/10.1590/S198177462009000100003.

Carneiro, M. J. (2008). "Rural" como categoria de pensamento. RURIS - Revista do Centro de Estudos Rurais, 2(1).
Recuperado de: https://www.ifch.unicamp.br/ojs/index.php /ruris/article/view/661. Acesso em: 10 jun. 2020.

Duarte, C. S. A. (2008). Constitucionalidade do direito à educação dos povos do campo. In Santos, C. (Org.). Campo - política pública - educação (pp. 33-38). Brasília: Nead.

Estevam, D. O. (2012). Casa Familiar Rural: a formação com base na Pedagogia da Alternância. (2. ed.). Florianópolis: Insular.

Ferreira, D. A. O., \& Ferreira, E. R. (2009). Estudos agrários: conceitos $e$ práticas. Rio Claro: IGCE/UNESP.

Frigotto, G. (1999). A produtividade da escola improdutiva. (5. ed.). São Paulo: Cortez.

Gil, A. C. (2010). Métodos e técnicas de pesquisa social. (6. ed.) São Paulo: Atlas.

Gritti, S. (2003). Educação rural e capitalismo. Passo Fundo: UPF.

Hernandez, F. (1998). A importância de saber como os docentes aprendem. Pátio Revista Pedagógica, [S.l.], (4).

Kerstenetzky, C. L. (2006). Políticas Sociais: focalização ou universalização?. Brazilian Journal of Political Economy [online], 26(4), 564-574. https://doi.org/10.1590/S0101$\underline{31572006000400006}$.

Martins, J. S. (1981). Introdução crítica à sociologia rural. São Paulo: Hucitec.

Matos, C. C., \& Rocha, G. O. R. (2020). O currículo da Educação do Campo no contexto das legislações nacionais. Revista Brasileira de Educação, [S.l.], 5, e4582. https://doi.org/10.20873/uft.rbec.e4582 
Molina, M. C. (2012). Políticas Públicas. In Caldart, R. S. (Org.). Dicionário da educação do campo (pp. 587-595). Rio de Janeiro: Escola Politécnica de Saúde Joaquim Venâncio; São Paulo: Expressão Popular.

Molina, M. C. (2008). A constitucionalidade e a justiciabilidade do direito à educação dos povos do campo. In Santos, C. (Org.). Campo - política pública - educação (pp. 19-31). Brasília, DF: Nead.

Moraes, R., \& Galiazzi, M. C. (2005). Análise Textual Discursiva. Ijuí, RS: Unijuí.

Paludo, C. (2001). Educação popular em busca de alternativas: uma leitura desde o campo democrático e popular. Porto Alegre: Tomo.

Petty, M., Tomnim, A., \& Vera, R. (1981). Uma alternativa de educação rural. In Werthein, J., \& Bordenave, J. D. (Orgs.). Educação rural no Terceiro Mundo (pp. 31-64). Rio de Janeiro: Paz e Terra.

Pistrak, M. M. (2000). Fundamentos da escola do trabalho. São Paulo: Expressão Popular.

Santos, J. R. (2012). A Educação numa perspectiva omnilateral: a práxis da relação entre educação, trabalho e movimentos sociais. Entrelaçando, [S.I.], 3(5), 92-102.

Souza, D. C. (2019). Políticas educacionais e concepção de educação no/do para o campo vinculadas aos cursos de Licenciatura em Ciências Agrícolas/Agrárias no Brasil. In Congresso Internacional de Direitos Humanos de Coimbra: uma visão transdisciplinar, 4., 2019, Coimbra. Anais... Coimbra, Portugal.

Wanderley. M. N. B. (2009). Agricultura Familiar e Campesinato: Rupturas e Continuidade. In Wanderley. M. N. B.
(Org.). O Mundo Rural como um Espaço de Vida (pp. 185-200). Porto Alegre: UFRGS.

\footnotetext{
i Este artigo está vinculado à linha de pesquisa "Desenvolvimento e Gestão Social" e ao Grupo de Pesquisa em Desenvolvimento Socioeconômico, Agricultura Familiar e Educação do Campo (GIDAFEC), do Programa de Pós-Graduação em Desenvolvimento Socioeconômico (PPGDS) (mestrado e doutorado) da Universidade do Extremo Sul Catarinense (UNESC). Os autores agradecem à Fundação de Amparo à Pesquisa e Inovação do Estado de Santa Catarina (FAPESC) e à Coordenação de Aperfeiçoamento de Pessoal de Nível Superior CAPES pela concessão de bolsa de mestrado para a primeira autora. Também há gratidão aos(às) colegas pesquisadores(as) professores(as) e discentes - pela atenta leitura crítica do material - aos(às) pareceristas anônimos(as) que contribuíram com sugestões relevantes para a versão final do artigo, à Carolina Garcia de Souza pela revisão do abstract, à Andreá Rubert pela revisão do Resumen e à Margareth Maria Kanarek da língua portuguesa. Por fim, destaca-se que uma versão preliminar, muito sucinta, do artigo foi publicada no IV Congresso Internacional de Direitos Humanos de Coimbra: uma visão transdisciplinar, realizado em outubro de 2019, na Universidade de Coimbra (Portugal).
}

Informações do Artigo / Article Information

Recebido em : 16/09/2020

Aprovado em: 15/03/2021

Publicado em: 30/11/2021

Received on September 16th, 2021

Accepted on March 15th, 2021

Published on November, 30th, 2021

Contribuições no Artigo: Os(as) autores(as) foram os(as) responsáveis por todas as etapas e resultados da pesquisa, a saber: elaboração, análise e interpretação dos dados; escrita e revisão do conteúdo do manuscrito e; aprovação da versão final publicada.

Author Contributions: The author were responsible for the designing, delineating, analyzing and interpreting the data, production of the manuscript, critical revision of the content and approval of the final version published. 
Conflitos de Interesse: Os(as) autores(as) declararam não haver nenhum conflito de interesse referente a este artigo.

Conflict of Interest: None reported.

\section{Avaliação do artigo}

Artigo avaliado por pares.

\section{Article Peer Review}

Double review.

\section{Agência de Fomento}

Fundação de Amparo à Pesquisa e Inovação do Estado de Santa Catarina - FAPESC.

\section{Funding}

Fundação de Amparo à Pesquisa e Inovação do Estado de Santa Catarina - FAPESC.

\section{Como citar este artigo / How to cite this article}

APA

Souza, D. C., Estevam, D. O., \& Gianezini, K. (2021). Interlocuções formativas contidas nos Projetos Políticos Pedagógicos dos cursos de Licenciatura em Ciências Agrícolas/Agrárias no Brasil. Rev. Bras. Educ. Camp., 6, e10495. http://dx.doi.org/10.20873/uft.rbec.e10495

\section{ABNT}

SOUZA, D. C.; ESTEVAM, D. O.; GIANEZINI, K. Interlocuções formativas contidas nos Projetos Políticos Pedagógicos dos cursos de Licenciatura em Ciências Agrícolas/Agrárias no Brasil. Rev. Bras. Educ. Camp., Tocantinópolis, v. 6, e10495, 2021. http://dx.doi.org/10.20873/uft.rbec.e10495 